OPEN ACCESS

Edited by:

Janice Siegford,

Michigan State University,

United States

Reviewed by:

Meagan King

University of Manitoba, Canada

Clive Julian Phillips,

Curtin University, Australia

${ }^{*}$ Correspondence:

Marian Stamp Dawkins

marian.dawkins@zoo.ox.ac.uk

Specialty section: This article was submitted to Precision Livestock Farming,

a section of the journal

Frontiers in Animal Science

Received: 05 July 2021 Accepted: 03 August 2021

Published: 23 August 2021

Citation

Dawkins MS (2021) Does Smart Farming Improve or Damage Animal

Welfare? Technology and What

Animals Want.

Front. Anim. Sci. 2:736536

doi: 10.3389/fanim.2021.736536

\section{Does Smart Farming Improve or Damage Animal Welfare? Technology and What Animals Want}

\author{
Marian Stamp Dawkins* \\ Department of Zoology, University of Oxford, Oxford, United Kingdom
}

"Smart" or "precision" farming has revolutionized crop agriculture but its application to livestock farming has raised ethical concerns because of its possible adverse effects on animal welfare. With rising public concern for animal welfare across the world, some people see the efficiency gains offered by the new technology as a direct threat to the animals themselves, allowing producers to get "more for less" in the interests of profit. Others see major welfare advantages through life-long health monitoring, delivery of individual care and optimization of environmental conditions. The answer to the question of whether smart farming improves or damages animal welfare is likely to depend on three main factors. Firstly, much will depend on how welfare is defined and the extent to which politicians, scientists, farmers and members of the public can agree on what welfare means and so come to a common view on how to judge how it is impacted by technology. Defining welfare as a combination of good health and what the animals themselves want provides a unifying and animal-centered way forward. It can also be directly adapted for computer recognition of welfare. A second critical factor will be whether high welfare standards are made a priority within smart farming systems. To achieve this, it will be necessary both to develop computer algorithms that can recognize welfare to the satisfaction of both the public and farmers and also to build good welfare into the control and decision-making of smart systems. What will matter most in the end, however, is a third factor, which is whether smart farming can actually deliver its promised improvements in animal welfare when applied in the real world. An ethical evaluation will only be possible when the new technologies are more widely deployed on commercial farms and their full social, environmental, financial and welfare implications become apparent.

Keywords: welfare, computer recognition, smart farming, precision, welfare algorithm

\section{INTRODUCTION}

Smart or precision farming involves the use of technology to monitor and manage the keeping of farm animals (Banhazi et al., 2012; Berckmans, 2017). It therefore includes sensors to measure a range of environmental and animal-based variables as well as the control mechanisms to make management decisions, either with or without human intervention. The ability to monitor animals continuously in real-time throughout their lives and to control their environments means that both productivity and welfare can potentially be improved through early detection of health problems 
(Wathes et al., 2008; Banhazi et al., 2012; Berckmans, 2017; Veissier et al., 2019), leading to targeted (and therefore reduced) use of medication, lower mortality and improved health. These outcomes in turn have other social benefits such as less waste, greater efficiency and lower environmental impact (Clark and Tilman, 2017; Perakis et al., 2020).

Furthermore, the smart data that can be collected from thousands of farms can be interrogated to find solutions to management, disease, welfare, productivity and even environmental issues that have previously been based only on the experience of one company or small-scale research projects. Intelligent use of the large data sets that smart farming makes possible can be used to further improve the results of smart farming itself.

On the other hand, however, precision farming also raises ethical concerns primarily because of its possible adverse effects on animal welfare (Wathes et al., 2008; Werkheiser, 2020). The concern is that gains in production and efficiency will lead to a deterioration in animal welfare through promotion of more intensive farming (Stevenson, 2017), an emphasis on group rather than individual welfare (Winckler, 2019) and the replacement of trained stock people by anonymous algorithms.

Although improved animal welfare is often one of the stated aims of smart farming (Rowe et al., 2019), it is far from clear that this is achieved in practice. One reason for this uncertainty is that much of the technology is still being developed and has not yet been widely enough applied in practice for its full implications to be clear. Precision agriculture as applied to livestock is therefore at a crucial stage where its impact on animal welfare could become either positive or negative. In this article, I shall argue that there are three factors that will largely determine the ultimate ethical verdict on smart farming. These are (i) whether smart farming adopts a definition of "animal welfare" that is acceptable to the public and in particular whether that definition includes the animals' point of view (ii) whether computer recognition of animal welfare is successful enough and is given high enough priority to satisfy the ethical standards that people demand and to genuinely improve welfare (iii) whether smart farming can actually deliver its promised improvements in animal welfare when applied in practice.

\section{AN AGREED DEFINITION OF ANIMAL WELFARE}

The first factor that will determine whether smart farming is seen as improving or damaging animal welfare is whether it will be possible to arrive at a definition of "welfare" that everyoneincluding scientists, farmers, animal charities and members of the public-can all agree on. This may sound like a trivial problem but in fact it is a serious stumbling block to a consensus view on the ethics of smart farming because there is currently no agreed definition of "welfare" in any context (Green and Mellor, 2011; Thompson, 2017; Ede et al., 2019; Weary and Robbins, 2019). For some people, "good welfare" must include making the animal's environment as "natural" as possible (Nussbaum, 2004; Yeates, 2018), while for others a natural life does not guarantee good welfare (Bracke and Hopster, 2006) and what animals need can be better met in a controlled, if artificial, environment in which technology plays a significant part (Gygax and Hillmann, 2018). The list of proposed measures of welfare now includes longevity (Hurnik, 1993), reproductive success (Broom, 1991), behavioral diversity (Rabin, 2003; Cronin and Ross, 2019), heart rate variability (von Borell et al., 2007; Kovacs et al., 2015), eye temperature (Gomez et al., 2018), skin temperature (Herborn et al., 2015) and hormone levels (Ralph and Tilbrook, 2016; Palme, 2019), along with many others. Such a plethora of different welfare "measures" means that what is an ethical way of keeping animals for one person is unethical for another. Without a definition of animal welfare that everyone can subscribe to and that genuinely improves animal welfare, precision farming could run into considerable opposition on the grounds that it does not meet the standards of a particular definition and does not live up to its promise of improving the lives of animals. For all the potential that Machine Learning has for determining the conditions that give rise to the best welfare outcomes, we still need a specification of what a "good" or desirable welfare outcome is (Morota et al., 2018).

A possible unifying definition of good welfare is that an animal is (i) in a state of good physical health and (ii) has what it wants (Dawkins, 2008, 2012, 2021). This is a distillation of many other widely used approaches such as the Ten General principles (OIE, 2012; Fraser et al., 2013), Five Freedoms (FAWC, 2009), the Five Provisions or Domains (Mellor, 2016), the Four Principles put forward by the Welfare Quality ${ }^{\circledR}$ project (Welfare Quality $^{\circledR}, 2018$ ) and the Three Circles of Welfare (Fraser, 2008) and so captures what many people from different perspectives mean by welfare (Dawkins, 2021). All of these schemes stress the fundamental importance of physical health to good welfare and "what animals want" gives a prominent place to the animals' own view of their environments (Welfare Quality ${ }^{\circledR}$, 2018; Franks, 2019). It is also in line with the recent trends to move away from defining welfare negatively as absence of suffering to defining it more positively so that animals have a Life Worth Living (LWL) or, even better, a positively Good Life (Broom, 2007; FAWC, 2009; Wathes, 2010; Green and Mellor, 2011; Webb et al., 2019). "What animals want" has been discussed in the scientific literature as animals having "positive emotions" (Boissy et al., 2007) or being in a "positive affective state" (Mendl et al., 2010; Gygax, 2017) but the simpler wording is more understandable to non-scientists and more directly indicative of the data that needs to be collected.

\section{COMPUTER RECOGNITION OF ANIMAL WELFARE}

Defining welfare explicitly in terms of health and what animals want has the further advantage that it lends itself directly to computer recognition of animal welfare. This is important because the ethical credentials of smart farming will depend to a very large extent on people being convinced that computers are capable of recognizing and assessing animal welfare and then that the computers are programmed to make sure that good welfare is a high priority. The definition of welfare used in 
smart farming must therefore be directly translatable into terms a computer can be programmed to recognize and apply in practice. The technology now available for smart farming includes "smart sensors" that collect real time information from animals and/or their environment (Neethirajan, 2017; Fogarty et al., 2018), the integration of different sorts of information into big data sets that can be used for Machine Learning to give the best production and welfare outcomes (Liakos et al., 2018; Bahlo et al., 2019) and systems that deliver fine control of an animal's environment and diet (Astill et al., 2020). Translating all of this data into practical improvements in welfare, however, depends crucially on how good computers are at interpreting the data they collect in welfare terms. How well are computers able to recognize the two elements of good welfare?

\section{Computer Recognition of Health and Disease}

Veterinary medicine has so far made much more limited use of computers to measure health than human medicine but there is now increasing use of automated methods for detecting signs of disease or injury in farm animals (Fournel et al., 2017; Awaysheh et al., 2019). This is most advanced in the dairy sector, where changes in the health status of each individual cow have an appreciable economic impact and so farmers find investment in the technology that gives detailed information on each animal to be important to their entire business (Lovarelli et al., 2020). For example, lameness in dairy cows can now be automatically detected in a variety of ways including visual images, accelerometer data from devices fitted to the cows' legs, pressure sensitive pads that record the way cows distribute their weight and even from the sound of their footfall (Alsaaod et al., 2019; Eckelkamp, 2019; Volkmann et al., 2019; Pilette et al., 2020). Changes in behavior such as longer bouts of lying, shorter bouts of feeding or ruminating can be automatically derived from visual images and accelerometers and serve as early warnings of both lameness and other health problems (Beer et al., 2016; Alsaaod et al., 2019; Eckelkamp, 2019; Grinter et al., 2019). In pigs, changes in tail position can be automatically detected by cameras and used as warnings for outbreaks of tailbiting, a serious source of injury (D'Eath et al., 2018). Digital imaging technology can also be used to analyze different postures indicating sick or injured birds (Zhuang et al., 2018) or to pick out lame broilers by abnormalities of their body oscillations, step frequency and step length (Aydin, 2017).

Large animals such as cows or sows can be individually monitored either by placing tags, trackers or measuring devices on or even inside each animal or by visually recognizing individual animals from camera data (Jorquera-Chavez et al., 2019; Sun et al., 2019; Baxter and O'Connell, 2020). Such devices can contribute to animal welfare by enabling each animal to have its own individualized diet and medical treatment (Caja et al., 2016). Computer vision and machine learning can now identify facial expressions of pain in sheep, giving early warning of diseases such as foot rot and mastitis and enabling an affected individual to be treated before the disease spreads to the rest of the flock (McLennan and Mahmoud, 2019).
However, where thousands of smaller animals are kept together, individual recognition is currently difficult and the entire group is assessed and treated as a whole. Commercially reared poultry, for example, do not have feed, vaccination, medication, drinker height, lighting and other factors adjusted for single individuals but, rather, set for the average needs of the entire flock. Welfare assessment is similarly based on group outcomes such as \% of a flock with gait defects, \% mortality, sounds or movements of whole flocks (Dawkins et al., 2012, 2017). This is one area where precision farming is currently limited but could in future make a real contribution to the welfare of group-housed animals. The "precision" in precision crop agriculture refers to the measurement of soil properties, moisture levels, weeds and diseases in specific parts of a field and the application of treatments such as fertilizers and herbicides precisely where these are really needed rather than to the field as a whole (Yufeng et al., 2011; Yost et al., 2017). The welfare of chickens could, similarly, benefit from technology that allowed farmers to identify injured birds and treat them individually or to be alerted to a particular areas of a house where a potential problem such smothering or over-crowding was beginning to occur. Houses containing many thousands of birds would no longer be treated as a single unit but as flocks of many individuals, experiencing different conditions and having different welfare outcomes. This would enable greater focus on the welfare of individual animals than either farmers or machines are able to do at the moment.

Even with current technology, however, valuable health information can be gained from monitoring the whole group without distinguishing individuals. For example, the sound of coughing has been used to automatically detect early signs of Bovine Respiratory Disease, despite the difficulties of distinguishing the sound of a cough from other background noises (Vandermeulen et al., 2016; Carpentier et al., 2018). The sounds of coughing in pigs (Silva et al., 2008) and sneezing in chickens (Carpentier et al., 2019) have also been used to detect respiratory diseases. Using visual images, broiler chicken flocks with high levels of leg damage and lameness can be automatically detected from anomalies in flock movement (Fernandez et al., 2018), even before these become apparent to the human eye (Dawkins et al., 2012, 2017, 2021; Zhuang et al., 2018).

It is thus clear that technology already has the ability to measure at least one element of good welfare-animal healthat both individual and group level. New automated ways of doing this are rapidly being developed and their use is likely to increase markedly in the near future as diagnostic tools become better able to focus on individual animals and to give early warning of incipient health problems (Eckelkamp, 2019; Wurtz et al., 2019; Li et al., 2020; Rios et al., 2020).

\section{Computer Recognition of What Animals Want (the Animal's Point of View)}

While signs of ill-health are comparatively easy for computers to recognize, there is more to good welfare than just absence of injury and disease and so a key question is whether computers 
are also capable of delivering on the second component of animal welfare-what animals want.

\section{Specifying Welfare Algorithms}

The success of an algorithm to detect when animals have what they want will depend on a computer being able to discriminate between the behavior or physiological state of animals that have what they want and the behavior or physiological state of animals that do not have what they want. Animal welfare scientists have already made great progress in drawing up these "body language" lists for different species and indeed they are often used as measures of either positive or negative welfare. Many can now be detected automatically with sensors, including hormone levels, activity levels, vocalizations, skin temperature, eye temperature, pupil size, heart rate variability and many more.

With such a large number of measures now available, there would appear to be a strong empirical base from which to develop welfare algorithms suitable for inclusion in smart farming systems. Unfortunately, it turns out that many of these measures are problematic because they fail to discriminate between animals having what they want and the complete opposite-animals not having what they want or being forced to remain in conditions they want to avoid or escape from. For example, cows showed a decrease in eye temperature when confined in a cattle crush to have their feet trimmed but also when given highly palatable food (Gomez et al., 2018). Large increases in glucocorticoid levels (often called "stress" hormones) are shown by animals that have what they want (such as food, voluntary exercise or a sexual partner) as well as by animals that want to escape or avoid something (Rushen, 1986; Koolhaas et al., 2011; Ralph and Tilbrook, 2016).

This ambiguity of many currently used measures of welfarethe fact that many can be interpreted as much as expressions of an excited animal having what it wants as an aroused animal attempting to avoid what is not wanted-means that an extra test needs to be applied before any should used in a welfare algorithm. That test is empirical evidence that the measure used is a genuine diagnostic of whether the animals themselves regard a given situation as something they want to continue/repeat (that is, they find it positive or rewarding) or as something they want to avoid (negative or punishing) (Dawkins, 1990, 2021; Guesgen and Bench, 2017; Gygax, 2017; Franks, 2019). This positive/negative classification is also called valence (Mendl et al., 2010).

\section{Determining Valence}

There are now a number of well-tried and tested ways of finding out what animals want including operant conditioning (Kilgour et al., 1991; Patterson-Kane et al., 2008), various sorts of choice tests, spatial distribution and other more indirect methods (Dawkins, 2021). The simplest of these include offering animals choices between various options and seeing which one they choose initially or where they go over a longer period. For example, when broiler chickens are offered a choice between traditional bar perches and platform perches, they spend considerably more time on the platforms than the bars, particularly as they get older, heavier and find it more difficult to balance on bars (Baxter et al., 2020). Their point of view is expressed in where they choose to spend their time.

Evidence of what animals want becomes even more convincing if animals can be shown to actually "work" to get what they want or pay a cost to obtain their reward. For example, dairy cows will learn to operate a switch to activate the motors of rotating brushes, which they then rub up against to groom themselves (Westerath et al., 2014). Furthermore, they will make great efforts to get to these brushes if it is made more difficult for them, for example if they have to push open a heavy gate (McConnachie et al., 2018). Cows clearly want the physical grooming provided by the brushes.

Traditionally, studies of animal choices and resource use are conducted by direct human observation or tedious analysis of video, which greatly limits their scope. Long-term computer analysis of where animals spend their time and how often and how much they will work for different resources provides much more quantitative data. It shows how choices change on a diurnal basis and as the animals age (Kashiha et al., 2014). It thus helps to overcome objections that have been raised to the use of choice tests in welfare assessment (Fraser and Nicol, 2011) such as animals not being familiar with the options available, the choices changing with experience or animals initially "wanting" something but then not "liking" it when they obtain it (Berridge et al., 2009).

\section{The Expression of Valence}

Although establishing what animals want is an essential first stage in the development of welfare algorithms, it is knowing how animals express themselves when they have (or do not have) what they want that enables the often ambiguous data from sensors to be correctly interpreted in welfare terms (Guesgen and Bench, 2017). Once it is known what animals want, then it is possible to observe them in the presence both of things or environments they have shown they want and in the presence of situations they have shown they want to avoid. If there are diagnostic differences between their behavior and physiology in these two situations-that is, reliable indicators of valence-then these are the ones that can be used with confidence as part of a welfare algorithm. These might be characteristic sounds, patterns of behavior or hormone profiles that enable a machine (or stockperson) to make a welfare assessment and any necessary management changes. For example, growing chicks give loud high high-pitched "distress" calls when they are cold, hungry, thirsty or isolated (i.e., do not have what they want) and soft, "twitter" calls when they are with the mother or other chicks, at the right temperature and otherwise have what they want (Collias and Joos, 1953; Wood-Gush, 1971). The calls are distinct and easy for both humans and computers to distinguish. The current welfare of chicks can therefore be assessed by monitoring these calls (Herborn et al., 2020), since their value as diagnostic valence indicators has already been established.

Computers, with their immense power to learn from large data sets could greatly increase the accuracy of welfare recognition algorithms and their ability to distinguish behavior of different valence. For example, the grunts emitted by pigs are different depending on whether the pigs are in situations they find 
rewarding or punishing (Leliveld et al., 2016), but there is a great deal overlap between the two categories of grunts, making them, at present, unreliable indicators of whether pigs have what they want (Friel et al., 2019). However, what we now see as unreliable signs of what the pigs want, could, with the power of machine learning to interpret them, become much more reliable, either because computers detect distinctions that escape us, or because they are able combine them with other behaviors and interpret them in context. Machine Learning, using very large data sets for training and testing deep learning models, will almost certainly detect as yet unknown correlations and insights into how to achieve better welfare outcomes than we currently have available (Liakos et al., 2018; Morota et al., 2018; Li et al., 2020).

There are, however, particular challenges posed by the automated analysis of behavior due to its variety. An animal that wants food will behave differently from the same animal when it wants a mate or wants warmth. Even wanting one thing such as food may sometimes take the form of searching a large area, at other times vocalizing and at yet other times sitting still to conserve energy. "Searching" in turn may consist of running, stalking, digging, turning over stones or any number of other behaviors that may themselves vary on different occasions even within the same individual. An added complication is that when the animal has found food, it will switch from "wanting" food to "liking" it (Berridge et al., 2009; Gygax, 2017) and show a whole new set of behavior associated with eating and post-prandial digestion. The body language list for recognizing when animals have what they want will therefore have to be extensive for each species and include this variety of different behaviors.

The list is likely to be even longer for how animals express themselves when they do not have what they want because there are so many different situations that animals may want to avoid or escape from, each giving rise to different behavior. An animal that does not have but can see what it wants (is "thwarted" or "frustrated") will behave differently from one in a barren environment (is "deprived" or "bored"). An animal that wants to avoid danger (is "fearful") will show a range of behaviors from vigilance to full-scale flight depending on the degree of danger. Aggression can take many forms and real fighting can actually look very similar to play fighting. The only thing that could unite these diverse behaviors and put them on the same negative list is that, from the animal's point of view, they are all indication of something that is not wanted nor liked.

Note that these animal-centered lists may not be the same as the lists that well-meaning humans, without the benefit of this background research, might come up with. For example, not all "natural" behaviors will make it to the positive list of what animals want. Some behaviors that occur naturally in the wild, such as being chased by a predator, may be the opposite of what an animal wants and be seen as indicative of poor welfare (Bracke and Hopster, 2006; Dawkins, 2021).

Once these lists have been compiled, however, they can be used to develop the validated welfare algorithms that smart farming needs if it is to be of practical use to farmers. Consumers can be assured that the welfare algorithms being used are based on what keeps animals healthy and also on the animals' own verdicts on what they do or do not want.

\section{Computers Can Provide What Animals Want}

More actively, computers can be used not just to measure what animals want but to actually give them what they want. Voluntary milking for cows (Munksgaard et al., 2011; Rodenberg, 2017) for example, or systems in which animals can control their own level of illumination (Taylor et al., 1996) show how smart farming could even lead to animal-centered environments in which animals adjust their environments to their own liking. The full welfare implications of this have yet to be understood.

\section{Some Remaining Problems With Machine Analysis of Welfare}

Having emphasized the role that computers could play in the recognition and assessment of animal welfare, it is important also to identify the problems that still remain. With sound, it may be difficult to distinguish vocalizations from background noise or there may be genuine overlap between vocalizations indicating positive or negative welfare.

With machine vision technology, there is an even greater range of technical problems still to be overcome (Dominiak and Kristensen, 2017; Liakos et al., 2018; Wurtz et al., 2019). The human brain is so good at recognizing people, subtle facial expressions, letters of the alphabet written in different scripts and objects that are only partially visible that it sometimes comes as a surprise that we still out-perform any computer on many of these visual tasks (Rolls, 2021). We excel at view-invariancethat is, at being able to recognize the same object even though its appearance may be very different depending on the angle, distance or orientation at which we see it. A pen looks long and thin when held one way but like a small round coin when looked at end-on but we still know it is a pen. A bus is still a bus to us even though half hidden by a wall so that it no longer has a typical bus shape. Such tasks are difficult for computers even with static objects presented in a uniform way (which is why tests of whether you are a robot on a website work). When confronted by active behavior sequences of moving animals seen from different angles, different distances from the camera, in different lighting conditions and often obscured by other animals, the task becomes even more difficult. If these problems are not solved satisfactorily, computer recognition will give false positive or false negative results, both of which detract from its usefulness in practice (Dominiak and Kristensen, 2017; Liakos et al., 2018).

Consequently, there is still a long way to go before welfare algorithms will do what is required of them as a reliable part of smart farming systems operating in commercial farm conditions (Wurtz et al., 2019). Progress is, however, being made all the time. The widespread use of video surveillance has driven the need for view-invariant computer recognition of different kinds of human activity that can operate independently of light level, camera angle background or other variables encountered in real life (Ramanathan et al., 2019; Singh et al., 2019). Such developments are of direct relevance to the problems of machine recognition of animal behavior in farm conditions (Li et al., 2021). 


\section{CAN SMART FARMING DELIVER ON ITS PROMISED BENEFITS TO ANIMAL WELFARE?}

Smart or precision livestock farming promises both greater efficiency to farmers and higher welfare standards for animals, but to quote a landmark paper by Wathes et al. (2008) it is still not clear whether smart farming is the animals "friend or foe" or the farmers "panacea or pitfall". Despite the major progress that has been made since this paper was published, precision livestock farming still lags behind plant crop production in its application of precision technology in many sectors (dairy farming being an exception). Many of its most ambitious features-such as automated welfare assessment-are still in the development phase (Rowe et al., 2019) and have yet to prove their value when applied to real farming conditions. As a result, many farmers particularly those in the poultry sector, are yet to be convinced that smart farming techniques are right for them or that they give any better results than be achieved without the help of expensive technology. Only when there is widespread commercial application and evidence of the results of smart farming in practice will we be able to judge its true outcomes. These outcomes will need to include whether it results in a reduction of waste, whether it reduces the incidence of disease and consequently reduces or increases the use of medication, what effects it has on the environment and the people working with animals and on whether it allows farmers to make a living.

Economic factors will be crucial. Only if farmers can see commercial benefits will they make the necessary investment in smart farming equipment and it is this emphasis on profit and efficiency that causes the most concern for animal welfare. There is a common belief that animal welfare is in conflict with efficient farming because its benefits are intangible and derive from ethics and moral values or what the public see as a "good" (Christensen et al., 2012). However, animal welfare also has direct financial benefits too and once these are appreciated animal welfare is less likely to be seen as in conflict with efficient farming (Guy et al., 2012; Dawkins, 2016). It is therefore worth considering the possible effects of smart farming on the two components of animal welfare discussed in this article in the light of their financial implications.

The impact of precision farming on the first component of animal welfare-good health-is likely to be positive and also to be financially beneficial. By having the greater control over environmental conditions that smart farming offers, animals can be kept in conditions that are optimal for their health, which makes them less likely to die or need medication or to be a source of disease to each other or to humans. Keeping broiler chickens within recommended limits of temperature and humidity, particularly during the first week of life, reduces not only mortality but other key health indicators as well such as hockburn, foot pad dermatitis and lameness (Dawkins et al., 2004; Jones et al., 2005). A broiler farm with 10 houses could be producing as many as 3 million birds a year so that even a $1 \%$ saving in mortality could be financially crucial for poultry producers. If the controlled environment achievable with precision farming also reduced downgrades due to leg and foot lesions, breast blisters and other signs of illhealth this could be an additional financial gain. Making sure that birds all grow at an even rate is another consideration with economic implications since supermarkets often demand birds all of the same weight. This is also important for bird welfare since underweight birds may find difficulty in accessing food and water. If precision farming results a higher percentage of saleable, healthy birds of even weight, farmers will gain financially and bird welfare will be improved at the same time.

With the second component of good welfare-animals having what they want-precision farming also has the potential to deliver efficiency and profit alongside better welfare. There is growing evidence that links "stress" to an impaired immune system (Hoerr, 2010; Inbaraj et al., 2019; Pratelli et al., 2021). In humans, good immune function is closely related to peoples' subjective reports of being happy and satisfied with their lives (Nakata et al., 2010; Takao et al., 2018), which is a promising model for relating immunity to non-human animals having what they want (Dawkins, 2019). This is an area where research is urgently needed, specifically to test the hypothesis that keeping animals in high welfare conditions (where they are both healthy and have what they want) boosts their immune systems, makes them more resistance to disease and leads to healthier more contented animals. If precision farming can provide the conditions that animals show by their behavior they want and like and they are also healthier, then this will provide a direct and immediate commercial advantage. If monitoring the animals' behavior can be shown to be useful in indicating when conditions are less than optimal from the animal's point of view, then the extra technology will have its own financial justification.

In addition to the direct financial benefits of giving priority to animal welfare, there are also indirect benefits, such as the public viewing farmers favorably and choosing to buy the products of precision farming because they are seen as "welfare friendly." This is likely to become increasingly important as new trade deals lead to greater competition and animal welfare becomes a key selling point for producers who can achieve it. A retailer or food outlet that is able reassure its customers that there is constant welfare monitoring on the farms it buys from and is able to explain what this means and even how the welfare is measured will be at a (commercial) advantage.

We do not yet know whether these promises of smart livestock farming will be fulfilled in practice. That will only become clear as systems become more widely used and as the smart systems themselves become more fully developed. Large data sets that can be interrogated by deep learning techniques will be crucial both to evaluating the effects of smart farming and to improving what it can achieve. Of these effects, animal welfare will be key to the future of smart farming, both as a major factor in its financial success or failure but more importantly as its ethical judge. Smart farming may stand or fall by whether it really can improve the lives of animals. 


\section{CONCLUSIONS}

Smart or precision farming is a collection of relatively new technologies whose effects on animal welfare have yet to become clear. The ethical verdict on smart farming is likely to depend on how the technology is developed over the next few years and how much priority is given to animal welfare. Three developments will be crucial to the ethical evaluation of smart farming in its treatment of animals: the definition of "welfare" it adopts,

\section{REFERENCES}

Alsaaod, M., Fadui, M., and Steiner, A. (2019). Automated lameness detection in cattle. Vet. J. 246, 35-44. doi: 10.1016/j.tvjl.2019.01.005

Astill, J., Dara, R. A., Fraser, E. D. G., Roberts, B., and Sharif, S. (2020). Smart poultry management: smart sensors, big data, and the internet of things. Comput. Electron. Agr. 170:105291. doi: 10.1016/j.compag.2020. 105291

Awaysheh, A., Wilcke, J., Elvinger, F., Rees, L., Fan, W., and Zimmerman, K. L. (2019). Review of medical decision support and machine-learning methods. Vet. Pathol. 56, 512-525. doi: 10.1177/0300985819829524

Aydin, A. (2017). Development of an early-detection system for lameness in broilers using computer vision. Comp. Electron. Agr. 136, 140-145. doi: 10.1016/j.compag.2017.02.019

Bahlo, C., Dahlhaus, P., Thompson, H., and Trotter, N. (2019). The role of interoperative data standards in precision livestock farming in external livestock systems: a review. Comput. Electron. Agr. 156: 459-466. doi: 10.1016/j.compag.2018.12.007

Banhazi, T. M., Lehr, H., Black, J. L., Crabtree, H., Schofield, P., and Tscharke, M. (2012). Precision Livestock Farming: an international review of scientific and commercial aspects. Int. J. Agr. Biol. Eng. 5, 1-9. doi: 10.3965/j.ijabe.20120503.001

Baxter, M., and O'Connell, N. (2020). Testing ultra-wideband technology as a method of tracking growing broilers under commercial conditions. Appl. Anim. Behav. Sci. 233:105150. doi: 10.1016/j.applanim.2020.105150

Baxter, M., Richmond, A., Lavery, U., and O’Connell, N. E. (2020). Investigating optimal levels of perch provision for windowed broiler housing. Appl. Anim. Behav. Sci. 225:104967. doi: 10.1016/j.applanim.2020.104967

Beer, G., Alsaaod, M., Starke, A., Schuepbach-Regula, G., Müller, H., Kohler, P., and Steiner, A. (2016). Use of extended characteristics of locomotion and feeding behavior for automated identification of lame dairy cows. PLoS ONE 11:e0155796. doi: 10.1371/journal.pone.0155796

Berckmans, D. (2017). General introduction to precision livestock farming. Anim. Front. 7: 6-11. doi: 10.2527/af.2017.0102

Berridge,. K. C., Robinson, T. E., and Aldridge, J. W. (2009). Dissecting components of reward: "liking", "wanting" and learning. Curr. Opin. Pharmacol. 9, 65-73. doi: 10.1016/j.coph.2008.12.014

Boissy, A., Manteuffel, G., Jensen, M. B., Moe, R. O., Spruijt, B., Keeling, L. J., et al. (2007). Assessment of positive emotions to improve their welfare. Physiol. Behav. 92, 375-397. doi: 10.1016/j.physbeh.2007.02.003

Bracke, M. B. M., and Hopster, H. (2006). Assessing the importance of natural behaviour for animal welfare. J. Agric. Environ. Ethic. 19, 77-89. doi: 10.1007/s10806-005-4493-7

Broom, D. M. (1991). Animal welfare-concepts and measurement. J. Anim. Sci. 69: 4167-4175. doi: 10.2527/1991.69104167x

Broom, D. M. (2007). Quality of Life means welfare: how is it related to other concepts and assessed? Anim. Welfare 16, 43-53. doi: 10.1016/0376-6357(91)90014-Q

Caja, G., Castro-Costa, A., and Knight, C. H. (2016). Engineering to support wellbeing of dairy animals. J. Dairy Res. 83, 136-147. doi: 10.1017/S0022029916000261

Carpentier, L., Berckmans, D., Youssef, A., Berckmans, D., van Watertschoot, T., Johnston, D., et al. (2018). Automatic cough detection for bovin respiratory disease in a calf house. Biosyst. Eng. 173, S45-56. doi: 10.1016/j.biosystemseng.2018.06.018 computer recognition of welfare and crucially, whether the welfare of farmed animals is actually improved by the application smart farming technology.

\section{AUTHOR CONTRIBUTIONS}

The author confirms being the sole contributor of this work and has approved it for publication.

Carpentier, L., Vranken, E., Berckmans, D., Paeshuyse, J., and Norton, T. (2019). Development of sound-based poultry health monitoring tool for automated sneeze detection. Comput. Electron. Agr. 162, 573-581. doi: 10.1016/j.compag.2019.05.013

Christensen, T., Lawrence, A., Lund, M., Stott, A., and Sandøe, P. (2012). How can economists help to improve animal welfare? Anim.Welfare 21, 1-10. doi: 10.7120/096272812X13345905673449

Clark, M., and Tilman, D. (2017). Comparative analysis of environmental impacts of agricultural, input efficiency and food choice. Environ. Res. Lett. 12:064016. doi: $10.1088 / 1748-9326 / \mathrm{aa} 6 \mathrm{~cd} 5$

Collias, N. E., and Joos, M. (1953). The spectrographic analysis of sound signals of the domestic fowl. Behaviour 5, 175-188. doi: 10.1163/156853953X00104

Cronin, K. A., and Ross, S. R. (2019). Technical contribution: a cautionary keynote on the use of behavioural diversity ( $\mathrm{H}$-index) in animal welfare science. Anim. Welfare 28, 157-164. doi: 10.7120/09627286.28.2.157

Dawkins, M. S. (1990). From an animal's point of view: motivation, fitness and animal welfare. Behav. Brain Sci. 13, 1-6. doi: 10.1017/S0140525X00077104

Dawkins, M. S. (2008). The science of animal suffering. Ethology 114, 937-945. doi: 10.1111/j.1439-0310.2008.01557.x

Dawkins, M. S. (2012). Why Animals Matter: Animal Consciousness, Animal Welfare and Human Well-being. Oxford: Oxford University Press.

Dawkins, M. S. (2016). Animal welfare and efficient farming: is conflict inevitable? Anim Prod. Sci. 57, 201-208. doi: 10.1071/AN15383

Dawkins, M. S. (2019). Animal welfare as preventative medicine. Anim. Welfare 28, 137-141. doi: 10.7120/09627286.28.2.137

Dawkins, M. S. (2021). The Science of Animal Welfare: Understanding What Animals Want. Oxford: Oxford University Press.

Dawkins, M. S., Cain, R., and Roberts, S. J. (2012). Optical flow, flock behaviour and chicken welfare. Anim. Behav. 84, 219-222. doi: 10.1016/j.anbehav.2012.04.036

Dawkins, M. S., Donnelly, C. A., and Jones, T. A. (2004). Chicken welfare is influenced more by housing conditions than by stocking density. Nature 427, 342-344. doi: 10.1038/nature02226

Dawkins, M. S., Roberts, S. J., Cain, R. J., Nickson, T., and Donnelly, C. A. (2017) Early warning of footpad dermatitis and hock burn in broiler chicken flocks using optical flow, body weight and water consumption. Vet. Rec.180, 448-452 doi: 10.1136/vr.104066

Dawkins, M. S., Wang, L., Ellwood, S. A., Roberts, S. J., and GebhardtHenrich, S. G. (2021). Optical flow, flock behaviour and broiler chicken welfare in the UK and Switzerland. Appl. Anim. Behav. Sci. 234:105180. doi: 10.1016/j.applanim.2020.105180

D'Eath, R. B., Jack, M., Futro, A., Talbot. D., Zhu, Q., Barclay, D., Baxter, E. M. (2018). Automatic early warning of tail biting in pigs: 3D cameras can detect lowered tail posture before an outbreak. PLOS One 13:e0194524. doi: 10.1371/journal.pone.0194524

Dominiak, K. N., and Kristensen, A. R. (2017). Prioritizing alarms from sensor-based detection models in livestock production: a review on model performance and alarm-reducing methods. Comp. Electron. Agr. 133, 46-67. doi: 10.1016/j.compag.2016.12.008

Eckelkamp, E. A. (2019). Invited review: current state of wearable precision dairy technologies in disease detection. Appl. Anim. Sci. 35, 209-220. doi: 10.15232/aas.2018-01801

Ede, T., Lecorps, B., von Keyserlingk, M. A. G., and Weary, D. M. (2019). Scientific assessment of affective states in dairy cattle. J. Dairy Sci. 102, 10677-10694. doi: 10.3168/jds.2019-16325 
FAWC (Farm Animal Welfare Council) (2009). Farm Animal Welfare in Great Britain: Past, Present and Future. FAWC, London.

Fernandez, A. P., Norton, T., Tullo, E., van Hertem, T., Youssef, A., Exxadaktylos, V., et al. (2018). Real-time monitoring of broiler flock's welfare status using camera-based technology. Biosyst. Eng. 173, 103-114. doi: 10.1016/j.biosystemseng.2018.05.008

Fogarty, E. S., Swain, D. L., Cronin, G., and Trotter, M. (2018). Autonomous onanimal sensors in sheep research: a systematic review. Comp. Electron. Agr. 150, 245-256. doi: 10.1016/j.compag.2018.04.017

Fournel, S., Rousseau, A. N., and Laberge, B. (2017). Rethinking environmental control strategy of confined animal housing systems through precision livestock farming. Biosyst. Eng. 155, 96-123. doi: 10.1016/j.biosystemseng.2016.12.005

Franks, B. (2019). What animals want. Anim. Welfare 28, 1-10. doi: 10.7120/09627286.28.1.001

Fraser, D. (2008). Understanding Animal Welfare: the Science in its Cultural Context. Universities Federation for Animal Welfare, Wiley-Blackwell, Chichester, UK.

Fraser, D., Duncan, I. J. H., Edwards, S. A., Grandin, T., Gregory, N. G., et al. (2013). General Principles for the welfare of animals in production systems: the underlying science and its application. Vet. J. 198, 19-27. doi: 10.1016/j.tvjl.2013.06.028

Fraser, D., and Nicol, C. J. (2011). "Preference and motivation research," in Animal Welfare, 2nd ed, eds M. C. Appleby, J. A. Mench, I. A. Olsson and B. O. Hughes (Wallingford, Oxfordshire: CABI), 183-199. doi: 10.1079/9781845936594.0183

Friel, M., Kunc, H. P., Griffin, K., Asher, L., and Collins, L. M. (2019). Positive and negative contexts predict duration of pig vocalisations. Sci. Rep. 9:2062. doi: 10.1038/s41598-019-38514-w

Gomez, Y., Bieler, R., Hankele, R., Zähner, M., Savary, P., and Hillmann, E. (2018). Evaluation of visible eye white and maximum eye temperature as noninvasive indicators of stress in dairy cows. Appl. Anim. Behav. Sci. 198, 1-8. doi: 10.1016/j.applanim.2017.10.001

Green, T. C., and Mellor, D. J. (2011). Extending ideas about animal welfare assessment to include 'quality of life' and related concepts. New Zeal. Vet. J. 59, 263-271. doi: 10.1080/00480169.2011.610283

Grinter, L. N., Campler, M. R., and Costa, J. H. C. (2019). Technical note: validation of a behavior-monitoring collar's precision and accuracy to measure rumination, feeding, and resting time of lactating dairy cows. J. Dairy Sci. 102: 3487-3494. doi: 10.3168/jds.2018-15563

Guesgen, M. J., and Bench, C. J. (2017). What can kinematics tell us about the affective states of animals? Anim. Welfare 25, 383-387. doi: 10.7120/09627286.26.4.383

Guy, J. H., Cain, P. J., Seddon, Y. M., Baxter, E. M., and Edwards, S. A. (2012). Economic evaluation of high welfare indoor farrowing systems for pigs. Anim. Welfare 21, 19-24. doi: 10.7120/096272812X13345905673520

Gygax, L. (2017). Wanting, liking and welfare: the role of affective states in proximate control of behaviour in vertebrates. Ethology 123, 689-704. doi: 10.1111/eth.12655

Gygax, L., and Hillmann, E. (2018). "Naturalness" and its relation to animal welfare from an ethological perspective. Agriculture 8:136. doi: 10.3390/agriculture 8090136

Herborn, K. A., McElligott, A. G., Mitchell, M. A., Sandilands, V., Bradshaw, B., and Asher, L. (2020). Spectral entropy of early-life distress calls as an iceberg indicator of chicken welfare. J. R. Soc. Interface 17:167. doi: $10.1098 /$ rsif.2020.0086

Herborn, K. A., Graves, J. L., Jerem, P., Evans, N. P., Nager, R., McCafferty, D. J., et al. (2015). Skin temperature reveals the intensity of acute stress. Physiol. Behav. 15, 225-230. doi: 10.1016/j.physbeh.2015.09.032

Hoerr, F. J. (2010). Clinical signs of immunosuppression in poultry. Avian Dis. 54, 2-15. doi: 10.1637/8909-043009-Review.1

Hurnik, J. F. (1993). Ethics and animal agriculture. J. Agric. Environ. Ethic. 6, 21-35.

Inbaraj, S., Sejian, V., and Ramasamy, S. (2019). Role of environmental stressor-host immune system-pathogen interactions in development of infectious disease in farm animals. Biol. Rhythm Res. 2019, 1-18. doi: 10.1080/09291016.2019.1695084

Jones, T. A., Donnelly, C. A., and Dawkims, M. S. (2005). Environmental and management factors affecting the welfare of chickens on commercial farms in the United Kingdom and Denmark stocked at five densities. Poult. Sci. 84, 1155-1165. doi: 10.1093/ps/84.8.1155

Jorquera-Chavez, M., Fuentes, S., Dunshea, F. R., Warner, R. D., Poblete, T., and Jogman, E. C. (2019). Modelling and validation of computer vision techniques to assess heart0rate, eye temperature, ear-base temperature and respiration rate in cattle. Animals 9:1089. doi: 10.3390/ani9121089

Kashiha, M. A., Green, A. R., Sales, T. G., Bahr, C., Berckmans, D., and Gates, R. (2014). Performance of an image processing system for hen tracking in an environmental preference chamber. Poult. Sci. 93, 2439-2445. doi: 10.3382/ps.2014-04078

Kilgour, R., Foster, T. M., Temple, W., Matthews, L. R., and Bremner, K. J. (1991). Operant technology applied to solving farm animal problems. An assessment. Appl. Anim. Behav. Sci. 30, 141-166. doi: 10.1016/0168-1591(91)90092-C

Koolhaas, J. M., Bartomolomucci, A., Buwalda, B., de Boer, S. F., Flugge, G., Korte, S. M., et al. (2011). Stress revisited: a critical evaluation of the stress concept. Neurosci. Biobehav. Rev. 35, 1291-1301. doi: 10.1016/j.neubiorev.2011.02.003

Kovacs, L., Kezer, L., Kezer, F. L., Jurkovich, V., Kulcsar-Huszenicza, M., and Tozser, J. (2015). Heart rate varisability as an indicator of chronic stress caused by lameness in dairy cows. PLoS ONE 1:e0134792. doi: 10.1371/journal.pone. 0134792

Leliveld, L. M. C., Dupjan, S., Tuchscherer, A., and Puppe, B. (2016). Behavioural and physiological measures indicate subtle variations in the emotional valence of young pigs. Physiol. Behav. 157, 116-124. doi: 10.1016/j.physbeh.2016.02.002

Li, G. M., Hueng, Y. B., Chen, Z. Q., Chesser, G., D., Purswell, J., et al.(2021). Practices and applications of convolutional neural networkbased computer vision systems in animal farming: a review. Sensors 21:1492. doi: $10.3390 / \mathrm{s} 21041492$

Li, N., Ren, Z., Li, D., and Zeng, L. (2020). Review: automated techniques for monitoring the behaviour and welfare of broilers and laying hens: towards the goal of precision livestock farming. Animal 14, 617-625. doi: 10.1017/S1751731119002155

Liakos, K. G., Busato, P., Moshou, D., Pearson, S., and Bochtids, D. (2018). Machine learning in agriculture: a review. Sensors 18:2674. doi: $10.3390 / s 18082674$

Lovarelli, D., Becenetti, J., and Guarino, M. (2020). A review of cattle farming: is precision livestock farming the compromise for an environmental, economic and social sustainable production. J. Clean. Prod. 262:121409. doi: 10.1016/j.jclepro.2020.121409

McConnachie, E., Smid, A. M. C., Thompson, A. J., Weary, D. M., Gaworski, M. A., and von Keyserlingk, M. A. G. (2018). Cows are highly motivated to access a grooming substrate. Biol. Lett. 14:20180303. doi: 10.1098/rsbl.2018.0303

McLennan, K., and Mahmoud, M. (2019). Development of an automated pain facial expression detection systems for sheep (Ovis aries). Animals 9:196 doi: 10.3390/ani9040196

Mellor, D. J. (2016). Updating animal welfare thinking: moving beyond the 'Five Freedoms' towards 'a life worth living'. Animals 6:21. doi: 10.3390/ani6030021

Mendl, M., Burman, O. H. P., and Paul, E. S. (2010). An integrative and functional framework for the study of animal emotions and mood. Proc.R. Soc. B 277, 2895-2904. doi: 10.1098/rspb.2010.0303

Morota, G., Ventura, R. V., Silva, F. F., Koyama, M., and Fernandez, S. C. (2018). Machine learning and data mining advance predictive big data analytics in precision animal agriculture. J. Anim. Sci. 96, 1540-1550. doi: $10.1093 /$ jas/sky014

Munksgaard, L., Rushen, J., de Passillé, A. M., and Krohn, C. C. (2011). Forced versus free traffic in an automated milking system. Livest. Sci. 138, 244-250. doi: 10.1016/j.livsci.2010.12.023

Nakata, A., Takahashi, M., Irie, M., and Swanson, N. G. (2010). Job satisfaction is associated with elevated natural killer cell immunity among healthy white-collar employees. Brain Behav. Immun. 24, 1268-1275. doi: 10.1016/j.bbi.2010.05.004

Neethirajan, S. (2017). Recent advances in wearable sensors for animal health management. Sensing Bio-sens. Res. 12, 16-29. doi: 10.1016/j.sbsr.2016.11.004

Nussbaum, M. C. (2004). "Beyond compassion and humanity. Justice for nonhuman animals," in Animal Rights: Current Debates and New Directions, eds C. S. Sunstein and M. C. Nussbaum (Oxford: Oxford University Press), Chapter 14, 299-320. doi: 10.1093/acprof:oso/9780195305104.003.0015

OIE (World Organization for Animal Health) (2012). Global Animal Welfare Strategy. OIE, Paris, France. Available online at: http://www.oie.int/fileadmin/ 
Home/eng/Animal_Welfare/docs/pdf/Others/EN_OIE_AW_Strategy.pdf (accessed May 8, 2020)

Palme, R. (2019). Non-invasive measurement of glucocorticoids: advances and problems. Physiol. Behav. 199, 229-243. doi: 10.1016/j.physbeh.2018.11.021

Patterson-Kane, E. G., Pittman, M., and Pajor, E. A. (2008). Operant animal welfare: productive approaches and persistent difficulties. Anim. Welfare. 17, 139-148.

Perakis, K., Lampathaki, F., Fenareti, L., Nikas, K., Georgiou, Y., Marko, O., et al. (2020). CYBELE-Fostering precision agriculture and livestock farming through secure access to large-scale HPC-enabled virtual industrial experimentation environments fostering scaleable big data analytics. Comput. Netw. 168:107035. doi: 10.1016/j.comnet.2019.107035

Pilette, D., Norton, T., Exadaktylos, V., and Berckmans, D. (2020). Individualized automated lameness detection in dairy cows and he impact of historical window length on algorithm performance. Animal 1, 409-417. doi: $10.1017 /$ S1751731119001642

Pratelli, A., Cirone, F., Capozza, P., Trotta, A., Corrente, M., Balestrieri, A., and Buonavoglia, C. (2021). Bovine respiratory disease in beef calves supported long transport stress: an epidemiological study and strategies for control and prevention. Res. Vet. Sci. 35, 450-455. doi: 10.1016/j.rvsc.2020.11.002

Rabin, L. A. (2003). Maintaining behavioural diversity in captivity for conservation: natural behaviour management. Anim. Welfare 12, 85-94.

Ralph, C. R., and Tilbrook, A. J. (2016). The usefulness of measuring glucocorticoids for assessing animal welfare. J. Anim. Sci. 34, 457-470. doi: $10.2527 /$ jas.2015-9645

Ramanathan, M., Yau, W. Y., Thalmann, N. M., and Teoh, E. K. (2019). Mutually reinforcing notion-pose for invariant action recognition. Int. J. Biomet. 11, 113-147. doi: 10.1504/IJBM.2019.099014

Rios, H. V., Waquil, P. D., de Carvalho, P. S., and Norton, T. (2020). How are information technologies addressing broiler welfare? A systematic review based on the Welfare Quality (R) Assessment. Sustainability 12:1413. doi: $10.3390 /$ su12041413

Rodenberg, J. (2017). Robotic milking: technology, farm design and effects on work flow. J. Dairy Sci. 100, 7729-38. doi: 10.3168/jds.2016-11715

Rolls, E. T. (2021). Learning invariant object and spatial view representations in the brain using slow unsupervised learning. Front. Comput. Neurosci. 15:686239. doi: $10.3389 /$ fncom.2021.686239

Rowe, E., Dawkins, M. S., and Gebhardt-Henrich. (2019). A systematic review of precision livestock farming in the poultry sector: is technology focused on improving bird welfare? Animals 9:614. doi: 10.3390/ani9090614

Rushen, J. (1986). Some problems with the physiological concept of 'stress'. Aust. Vet. J. 63, 359-361. doi: 10.1111/j.1751-0813.1986.tb02896.x

Silva, M., Ferrari, S., Costa, A., Aerts, J. M., Guarino, M., and Berckmans, D. (2008). Cough localization for the detection of respiratory diseases in pig houses. Comput. Electron. Agr. 64, 286-292. doi: 10.1016/j.compag.2008.05.024

Singh, R., Kushwaha, A. K. S., and Srivastava, R. (2019). Multi-view recognition system for human activity based on multiple features for video surveillance system. Multimed. Tools Appl. 78, 17165-17198. doi: 10.1007/s11042-018-7108-9

Stevenson, P. (2017). Precision Livestock Farming: Could it Drive the Livestock Sector in the Wrong Direction. Available online at: https://www.ciwf.org/ research/animal-welfare/precision-livestock-farming-could-it-drive-thelivestock-sector-in-the-wrong-direction/ (accessed August 18, 2020).

Sun, Y. K., Huo, P. J., Wang, Y. J., Cui, Z. Q., Li, Y., Dai, B. S., et al. (2019). Automatic monitoring system for individual dairy cows based on a deep learning framework that provides identificatiob via body parts and estimation of body condition score. J. Dairy Sci. 102, 10140-10151. doi: $10.3168 /$ jds.2018-16164

Takao, Y., Okuno, Y., Mori, Y., Asada, M., Yamanishi, K., and Iso, H. (2018). Associations of perceived mental stress, sense of purpose in life, and negative life events with the risk of incidental Herpes zosta and post herpetic neuralgia. Am. J. Epidemiol. 187, 251-259. doi: 10.1093/aje/kwx249

Taylor, N., Prescott, N., Perry, G., Potter, M., Le Sueur, C., and Wathes, C. (1996). Preference of growing pigs for illuminance. Appl. Anim. Behav. Sci. 96, 19-31. doi: 10.1016/j.applanim.2005.04.016

Thompson, P. B. (2017). From Field to Fork: Food Ethics for Everyone, $2^{\text {nd }}$ ed. Oxford: Oxford University Press.

Vandermeulen, J., Bahr, C., Johnston, D., Earley, B., Tullo, E., et al. (2016). Early recognition of bovine respiratory disease in calves using continuous monitoring of cough sounds. Comp. Electron. Agr.129, 15-26. doi: 10.1016/j.compag.2016.07.014

Veissier, I., Kling-Eveillard, F., Mialon, M. M., Silberberg, M., De Boyer Des Roches, A., et al. (2019). Precision livestock farming and animal welfare: is the numerical revolution in agriculture able to take into account animals' and farmers' needs? INRA Prod. Anim. 32, 281-290. doi: 10.20870/productions-animales.2019.32.2.2478

Volkmann, N., Kulig, B., and Kemper, N. (2019). Using the foortfall sound of dairy cows for detecting claw lesions. Animals 9:78. doi: 10.3390/ani9030078

von Borell, E., Langbein, J., Desprès, G., Hansen, S., Leterrier, C., Marchent-Forde, J., et al. (2007). Heart rate variability as a measure of autonomic regulation of cardiac activity for assessing stress and welfare in farm animals-a review. Physiol. Behav. 92, 293-316. doi: 10.1016/j.physbeh.2007.01.007

Wathes, C. M. (2010). Lives worth living? Vet. Rec. 166, 468-9. doi: 10.1136/vr.c849

Wathes, C. M., Kristensen, H. H., Aerts, J.-M., and Berckmans, D. (2008)|Is precision livestock farming an engineer's daydream or nightmare, an animal's friend or foe, and a farmer's panacea or pitfall? Comp. Electron. Agr. 64, 2-10. doi: 10.1016/j.compag.2008.05.005

Weary, D. M., and Robbins, J. A. (2019). Understanding the multiple conceptions of animal welfare. Anim. Welfare 28, 33-40. doi: 10.7120/09627286.28.1.033

Webb, L. E., Veenhoven, R., Harfield, J. L., and Jensen, M. B. (2019). What is animal happiness? Ann. NY Acad. Sci. 438, 62-76. doi: 10.1111/nyas.13983

Welfare Quality ${ }^{\circledR}(2018)$. Available online at: http://www.EUwelfarequality.net/ en-us/home/ (accessed May 25, 2020).

Werkheiser, I. (2020). Technology and responsibility: a discussion of underexamined risks and concerns in Precision Livestock Farming. Anim. Front. 10, 51-56. doi: 10.1093/af/vfz056

Westerath, H. S., Gygax, L., and Hillmann, E. (2014). Are special feed and being brushed judged positive by calves? Appl. Anim. Behav. Sci. 156, 12-21. doi: 10.1016/j.applanim.2014.04.003

Winckler, C. (2019). Assessing animal welfare at the farm level: do we care sufficiently about the individual? Anim. Welfare 28, 77-82. doi: 10.7120/09627286.28.1.077

Wood-Gush, D. G. M. (1971). The Behaviour of the Domestic Fowl. London: Heinemann Educational Books.

Wurtz, K., Camerlink, I., D’Eath, R. B., Fernandez, A. P., Norton, T., Steibel, J., et al. (2019). Recording behaviour of indoor-housed farm animals automatically using machine vision technology: a systematic review. PLoS ONE 14:e0226669. doi: 10.1371/journal.pone.0226669

Yeates, J. W. (2018). Naturalness and animal welfare. Animals 8:53 doi: $10.3390 /$ ani 8040053

Yost, M. A., Kitchen, N. R., Sudduth, K. A., Sadler, E. J., Drummond, S. T., and Volkmann, M. R. (2017). Long-term impact of a precision agriculture system on grain crop production. Precis Agric. 18, 823-842. doi: 10.1007/s11119-016-9490-5

Yufeng, G. E., Thomasson, A., and Ruixiu, S. (2011). Remote sensing of soil properties in precision agriculture: a review. Earth Sci. 5,

Zhuang, X. L., Bi, M. N., Guo, J. L., Wu, S. Y., and Zhang, T. M. (2018). Development of an early warning algorithm to detect sick broilers. Comp. Electron Agr. 144, 102-113. doi: 10.1016/j.compag.2017.11.032

Conflict of Interest: The author declares that the research was conducted in the absence of any commercial or financial relationships that could be construed as a potential conflict of interest.

Publisher's Note: All claims expressed in this article are solely those of the authors and do not necessarily represent those of their affiliated organizations, or those of the publisher, the editors and the reviewers. Any product that may be evaluated in this article, or claim that may be made by its manufacturer, is not guaranteed or endorsed by the publisher.

Copyright (C) 2021 Dawkins. This is an open-access article distributed under the terms of the Creative Commons Attribution License (CC BY). The use, distribution or reproduction in other forums is permitted, provided the original author(s) and the copyright owner(s) are credited and that the original publication in this journal is cited, in accordance with accepted academic practice. No use, distribution or reproduction is permitted which does not comply with these terms. 